Discussion Paper No. 10-095

Consumer Welfare and Unobserved Heterogeneity in Discrete Choice Models: The Value of Alpine Road Tunnels

Daniel Cerquera and Hannes Ullrich

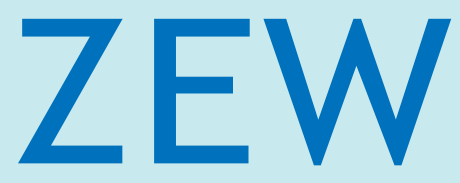

Zentrum für Europäische Wirtschaftsforschung $\mathrm{GmbH}$

Centre for European

Economic Research 
Discussion Paper No. 10-095

\section{Consumer Welfare and Unobserved Heterogeneity in Discrete Choice Models: The Value of Alpine Road Tunnels}

Daniel Cerquera and Hannes Ullrich

Download this ZEW Discussion Paper from our ftp server:

ftp://ftp.zew.de/pub/zew-docs/dp/dp10095.pdf

Die Discussion Papers dienen einer möglichst schnellen Verbreitung von neueren Forschungsarbeiten des ZEW. Die Beiträge liegen in alleiniger Verantwortung der Autoren und stellen nicht notwendigerweise die Meinung des ZEW dar.

Discussion Papers are intended to make results of ZEW research promptly available to other economists in order to encourage discussion and suggestions for revisions. The authors are solely responsible for the contents which do not necessarily represent the opinion of the ZEW. 


\section{Non-technical summary}

We investigate consumer welfare in transalpine freight transport using micro-data on individual route choice, tackling two core questions. First, to what extent does the way we model unobserved heterogeneity matter for welfare estimates in discrete choice models? Second, what is the loss in consumer surplus per year from shutting down a transalpine road infrastructure such as the Mont Blanc tunnel? Closing this tunnel has been proposed in the political debate following several fatal road accidents in large alpine tunnels. The most severe accident, in the Mont Blanc in 1999, led to a full closure of the tunnel for a period of 3 years.

We model route choice as a discrete choice among a number of mutually exclusive alternatives. Due to our rich data, we can flexibly model unobserved heterogeneity of decision makers in their valuation of money and time. Decision makers may be heterogenous for a number of reasons. For example, the value of alternatives may depend on the weight or type of commodity a truck is transporting. These are examples for observable heterogeneity which are easily controlled for. However, the value of money and time is also likely to depend on unobservable truck characteristics. These could be en route pick-ups of goods, special logistic needs, or truck drivers' personal tastes that favor one route over another. Modeling such unobserved heterogeneity in the discrete choice framework has been at the heart of research analyzing economic choices during the last two decades. Only recently, researchers have started asking how the way we model unobserved heterogeneity affects policy-relevant measures of consumer welfare.

We contribute to this literature by applying a recently proposed flexible nonparametric estimator of unobserved heterogeneity to a random coefficients logit model and investigating the impact of parametric assumptions on a measure of consumer welfare. In a nutshell, the idea of the estimator is to approximate the true underlying taste distribution by a finite grid in the preference space. To our knowledge, we are the first to apply this estimator to real-world data in a static discrete choice model with random coefficients. To identify the underlying structural parameters, we use a large scale individual choice data set from the 2004 Cross-Alpine Freight Transport survey. We exploit exogenous variation in travel cost and time arising from the fixed geographic locations of origin, destination, and alpine crossing points. While endogeneity concerns are less important with individual-level data, we discuss several potential sources of endogeneity bias such as congestion or weather conditions.

We find that parametric assumptions and the dimensionality of modeled unobserved heterogeneity have a significant impact on welfare results. Our nonparametric estimates predict economically significantly higher annual losses in user surplus due to the MontBlanc tunnel closure. The latter implies a loss of $€ 5.39$ millions and the parametric random coefficients logit model a loss of $€ 2.97$ millions in specifications where both price and time are assumed to have random coefficients. With one random coefficient, the nonparametric estimate is almost double that of the parametric random coefficients logit estimate, $€ 7.09$ millions versus $€ 3.62$ millions. Compared to the logit with fixed coefficients and the nonparametric estimates, both parametric random coefficient specifications underestimate the loss in consumer surplus. 


\section{Das Wichtigste in Kürze}

Die Alpen stellen europäische Transportplaner vor große Herausforderungen. Dieses Nadelöhr zu überkommen ist nur über umständliche Alpenpässe möglich, oder durch Strassen- und Eisenbahntunnels, die teuer zu betreiben und nur anhand sehr grosser Investitionen zu bauen sind. Im Mittelpunkt vieler Diskussionen steht seit geraumer Zeit die Sicherheit des Strassengüterverkehrs und Politikmassnahmen die zu ihrer Verbesserung beitragen. Im Vordergrund steht meist die Förderung des Wechsels des Gütertransitverkehrs von der Strasse auf die Schiene. Insbesondere zwischen Italien und Frankreich findet dieser Wechsel jedoch nach wie vor nur begrenzt statt. Gleichzeitig kosteten wiederholte schwere Unfälle in den grossen Alpentunnels - Mont Blanc (1999), Tauern (1999), Gotthard (2001), Fréjus (2005) - zahlreiche Menschenleben und führten zu substantiellen Schliessungen einzelner Tunnels. Der Mont-Blanc Tunnel blieb nach dem Unfall für 3 Jahre geschlossen.

In dieser Studie untersuchen wir die jährlichen Wohlfahrtsverluste einer solchen Schliessung. Dabei berücksichtigen wir insbesondere die Modellierung unbeobachtbarer Heterogenität in einem Modell der transalpinen Routenwahl von Güterlastkraftwagen. Letztere können sich aus verschiedenen Gründen in ihrer Preis- und Zeitkostensensitivität unterscheiden. Zum Einen spielen Art und Gewicht der transportierten Ladung eine Rolle. Hierbei handelt es sich um beobachtbare Heterogenität, für die leicht kontrolliert werden kann. Zum Anderen ist anzunehmen, dass sich Transporte auch durch spezielle logistische sowie routenplanerische Eigenheiten oder auch persönliche Präferenzen einzelner LKWFahrer unterscheiden. Diese Merkmale sind für uns nicht beobachtbar. Die Modellierung solch unbeobachtbarer Heterogenität war und ist in der wirtschaftswissenschaftlichen Literatur von zentraler Bedeutung. Dagegen wurden bisher die Konsequenzen verschiedener Ansätze bezüglich politik-relevanter Masse, wie die Konsumentenrente, kaum thematisiert.

Der Beitrag dieser Studie ist die Anwendung eines kürzlich vorgeschlagenen nichtparametrischen Schätzers unbeobachtbarer Heterogenität im Rahmen des random coefficient logit Modells und der Vergleich der implizierten Konsumentenrenteschätzungen mit solchen, die auf gängigen parametrischen Methoden basieren. Des Weiteren quantifizieren wir die direkten jährlichen Wohlfahrtsverluste einer Schliessung des Mont-Blanc Tunnels für den Strassengüterverkehr. Hierfür verwenden wir einen umfassenden Datensatz individueller Routenentscheidungen aus der Cross-Alpine Freight Transport Erhebung im Jahr 2004.

Wir finden ökonomisch signifikante Unterschiede zwischen Wohlfahrtsschätzungen, die auf unterschiedlichen parametrischen Annahmen über unbeobachtbare Heterogenität basieren. Der jährliche Verlust an Konsumentenrente durch eine Schliessung des Mont-Blanc Tunnels, der durch unsere nicht-parametrischen Schätzungen vorhergesagt wird, ist deutlich höher als die aus parametrischen Schätzungen folgenden Ergebnisse. Während aus ersteren jährliche Verluste von $€ 5.39$ bis $€ 7.09$ Millionen resultieren, ergeben die Schätzungen aus dem parametrischen random coefficients logit Modell Verluste von $€ 2.97$ bis $€ 3.62$ Millionen. 


\title{
Consumer Welfare and Unobserved Heterogeneity in Discrete Choice Models: The Value of Alpine Road Tunnels*
}

\author{
Daniel Cerquera ${ }^{\dagger} \quad$ Hannes Ullrich ${ }^{\ddagger}$
}

\begin{abstract}
We investigate the sensitivity of consumer surplus estimates to parametric assumptions on individual preference heterogeneity in a discrete choice framework. We compare results from a parametric random coefficients logit model and a recently proposed nonparametric sieve estimator. In particular, we provide an assessment of the direct economic value of crossing the Alps for the European road freight sector. Using revealed preference data from a detailed survey on transalpine road freight traffic, we estimate the yearly cost of closing the Mont-Blanc Tunnel, which was closed for 3 years following a large accident in early 1999. Ultimately, our results permit the economic evaluation of security and transport policy measures affecting transalpine traffic. Our findings suggest that the way we model unobserved heterogeneity significantly affects our welfare results.
\end{abstract}

Keywords: Discrete Choice, Consumer Surplus, Nonparametric Estimation, Transalpine Freight.

JEL Classification: R41, C14, C35, L91, H54.

${ }^{*}$ We thank Tomaso Duso, Alexander Ebertz, Jeremy Fox, Ulrich Kaiser, Tobi Klein, Johannes Koenen, Francois Laisney, Christoph Nagel, Ricardo Ribeiro, Minjae Song, and participants at the RNIC Structural IO Workshop 2008 for helpful comments. Lukas Kornher provided excellent research assistance. We thank Michel Houée, Thomas Spiegel, and Walter Züst for help on using the CAFT data and the RNIC network for financial support.

$\dagger$ ZEW Centre for European Economic Research, Mannheim. E-Mail: cerquera@zew.de

$\ddagger$ ZEW Centre for European Economic Research, Mannheim, and University of Zurich. Corresponding Author, E-Mail: hannes.ullrich@zew.de 


\section{Introduction}

In devising informed policy measures, reliable estimates of welfare implications for affected individuals and firms are crucial. In many applied settings, decision makers face a set of mutually exclusive options. To evaluate, for example, changes in choice sets due to product entry/exit or changes in product characteristics in the discrete choice framework, the Hicksian compensating variation, derived by Small and Rosen (1981), has been used extensively in applied work. Prominent examples that estimate welfare implications using discrete choice models are Trajtenberg (1989), on the introduction of CT scanners, Goolsbee and Petrin (2002), on Satellite TV in the US, and Petrin (2004), on the introduction of the Minivan in the US automotive market. Much progress has been made in identifying and providing flexible ways of modeling unobserved consumer heterogeneity. The current workhorse model is the random coefficients, or mixed, multinomial logit model introduced by Boyd and Mellman (1980) and Cardell and Dunbar (1980). McFadden and Train (2000) have shown that it can approximate any random utility model arbitrarily well if the researcher knows the correct distribution of random coefficients a priori. Just as the above examples, most applied work has imposed parametric distributions on the coefficients over which individuals are assumed to differ. ${ }^{1}$

In this paper, we provide insights into the impact of distributional assumptions in modeling unobserved heterogeneity on welfare estimates. If the researcher aims to estimate consumer surplus, we expect an adequate representation of the true underlying distribution of tastes to be important. To investigate this expectation further, we consider alternative distributional assumptions in a transalpine route choice setup. We employ revealed preference data from a large-scale transport survey in 2004 and analyze the implications of a transport policy measure which has been debated in recent years: the closure of the Mont Blanc tunnel to freight traffic. In particular, we consider the choice of road tunnels by transalpine freight traffic, where individual decision makers face a set of mutually exclusive options. We proceed by estimating three discrete choice model specifications. First, the simple fixed coefficient logit model. Second, the parametric random coefficients logit model. Third, the nonparametric estimator of preference distributions recently proposed by Bajari et al. (2007, 2010), henceforth BFKR. For each specification, we estimate the loss in consumer surplus caused by a change in choice sets and compare the results. To our knowledge, we are the first to apply the BFKR estimator to real-world data in a random coefficients logit setting. Many applications have estimated welfare effects but we are not aware of many studies exploring the role of unobserved heterogeneity in this context. A notable exception are Hynes et al. (2008), who compare welfare implications of a random coefficients logit model and a latent class model of kayakers' destination choices of

\footnotetext{
${ }^{1}$ Standard choices have been the normal and the log-normal distributions.
} 
whitewater sites in Ireland. They find no significant differences in welfare results from both models.

The Alps are Europe's highest and most extensive mountain range running from Mediterranean France to southern Austria. With its extreme geography, the alpine region not only forms a natural frontier between Italy and central Europe, but provides the unique gateway for ground transport between southeastern European regions (and beyond) and central and northern Europe. Due to the limited number of crossing points, the Alps are a natural bottleneck at the core of European economic activity. After the introduction of the European single market, the opening of eastern Europe and the corresponding enlargement of commercial relations within the European Free Trade Association (EFTA), transalpine freight traffic has become not only an important topic in European politics but a key component of transport infrastructure planning. Mountainous road infrastructure exhibits elevated risks for its users, among others, due to its reliance on long underground passages. Tragic displays of this fact have been the accidents in the Mont Blanc tunnel in 1999, the Tauern tunnel in 1999, the Gotthard tunnel in 2001, and the Frejus tunnel in 2005. The most severe of these four accidents, in the Mont Blanc tunnel, cost 39 lives and lead to a full closure of the tunnel for three years.

These events have brought about policy initiatives in various forms. For the alpine regions, additional investment in security measures at tunnels and formulating the objective of shifting freight to rail and maritime transport have been particular examples. ${ }^{2}$ Prady and Ullrich (2010) find limited modal shift for freight traffic in their evaluation of a proposed rail tunnel connecting Lyon and Turin. Proposed safety measures have reached as far as the closure of certain road tunnels to freight traffic. ${ }^{3}$ Quantifying the short-term monetary loss incurred by the freight transport sector from the closure of a given tunnel is of interest to inform policy decisions for two main reasons. First, quantifying the monetary consequences of a potential closure for its users are at the core of any cost-benefit analysis. Second, the burden caused by unintended closures due to accidents must be known when assessing the monetary benefits of investment in safety measures. There are few studies evaluating the accidental or deliberate closure of transport infrastructure. One exception are Bilotkach et al. (2010) who exploit the collapse of a freeway interchange in the San Francisco Bay Area to analyze sensitivity of pricing behavior to demand shocks. In practice, removing transport infrastructure is not as exotic a discussion as one may think. In New York City, A recent debate has been ignited by the potential closure of an Expressway in the Bronx (see Dolnick, 2010).

To investigate the impact of distributional assumptions on welfare implica-

\footnotetext{
${ }^{2}$ See, for example, European Commission (2001, 2006) and Andrews (2001).

${ }^{3}$ See European Parliament (2001), and articles in the LA times (http://articles. latimes.com/2002/mar/10/news/mn-32111) and the BBC (http://news.bbc.co.uk/2/hi/ europe/1863245.stm).
} 
tions, we estimate the monetary relevance of alpine road infrastructure to road freight crossing the Western Alpine corridor. In particular, we estimate the monetary loss incurred by the freight transport sector due to a hypothetical closure of the Mont Blanc tunnel. We analyze a hypothetical closure since we cannot use the actual exogenous event in 1999 for identification as our data lacks withinyear time information. Our welfare analysis should be seen in a narrow sense. Total welfare encompasses not only direct changes in consumer surplus but also changes in external effects, e.g. caused by congestion or nuisances to other travelers, as well as macroeconomic variables such as regional development or trade. Particularly in the alpine regions, estimating the total social cost would need to include both the direct costs to users (changes in consumer surplus) and external effects on non-freight users (congestion, for example) and non-users of the infrastructure such as inhabitants of the respective alpine valleys. The monetary cost of injuries, property damage and business interruption should be more directly quantifiable while macro-economic effects on economic activity and trade are difficult to identify. Here we focus on direct short-term effects likely to be central to the current political discussion.

We find that both parametric assumptions and the dimensionality of modeled unobserved heterogeneity have a significant impact on welfare results. Our BFKR estimates predict economically significantly higher annual losses in user surplus due to the Mont Blanc tunnel closure. While the latter implies a loss of $€ 5.39$ millions, the parametric random coefficients logit model predicts a loss of $€ 2.97$ millions in specifications where both price and time are assumed to have random coefficients. With one random coefficient, the BFKR estimate is almost double that of the parametric random coefficients logit estimate, $€ 7.09$ millions versus $€ 3.62$ millions. Compared to the fixed coefficients logit and the BFKR estimates, both parametric random coefficient specifications underestimate the loss in consumer surplus.

The next section presents our data on freight traffic in the alpine region. Section 3 presents the empirical framework and discusses distributional assumptions and identification. We present our estimation results in Section 4, discuss the implied substitution pattern and welfare results in Section 5, and conclude in Section 6.

\section{Alpine Freight Traffic}

Our data is a large-scale cross-section from the Cross-Alpine Freight Transport (CAFT) survey done every 5 years. ${ }^{4}$ Each respective year, trucks are stopped and surveyed at all possible Alpine crossings between Vintimille and Wechsel (see Figure 2). The survey is a joint initiative by the Austrian, French, and Swiss governments to produce a representative sample of transalpine freight transport. In

\footnotetext{
${ }^{4}$ The available waves are 1994, 1999, and 2004 with data quality increasing in each wave.
} 
2004, Germany and Italy joined the effort emphasizing the political relevance of collecting high quality data on transalpine transport activity. The data set comprises detailed information on each truck's origin and destination regions. Regions are defined at the NUTS3 level, corresponding, for example, to departments in France, districts in Germany, counties in the US. The data further include transported commodity classes, weight, vehicle characteristics, region of registration, intermediary boarder crossings, traffic direction, and more. We merge this data with shortest distances on a direct line, data on average gas and other operating costs, road and tunnel tolls, as well as with GDP data on origin and destination regions. ${ }^{5}$ Our sample includes all French-Italian passages and all Swiss-Italian passages (see Appendix and Figure 2).

Table 1: Alternative-specific characteristics

\begin{tabular}{|c|c|c|}
\hline & Mean & $\begin{array}{l}\text { Standard } \\
\text { Deviation }\end{array}$ \\
\hline \multicolumn{3}{|l|}{ Alternative characteristics } \\
\hline Price & 362.7 & 148.1 \\
\hline Distance & 853.2 & 413.5 \\
\hline Time & 18.4 & 11.6 \\
\hline \multicolumn{3}{|l|}{ User (truck) characteristics } \\
\hline Weight of goods (tons) & 12.8 & 8.8 \\
\hline Per capita GDP at destination & $30,788.1$ & $11,299.7$ \\
\hline
\end{tabular}

Notes: The CAFT 2004 survey includes 285,656 observations and 35,707 choice situations on French and Swiss passages.

In Table 1 we present descriptive statistics of our variables. We compute price based on an average per kilometer cost estimated by the French Comité National Routier on an annual basis ${ }^{6}$ and Alpine tunnel fees. For Swiss passages, we include the Heavy Vehicle Fee which is based on ton-kilometers in Switzerland. These fees provide exogenous variation at the level of individual trucks since they are set by the regulator, irrespective of congestion or other choice-specific characteristics which we cannot observe. We compute distance in kilometers from origin to destination regions via each respective Alpine passage using Vincenty

\footnotetext{
${ }^{5}$ We also collected data on daily weather conditions during the sample period. Unfortunately, only the French part of the sample includes observation dates and we cannot use this information. Since mainly small and high-altitude passes are negatively affected by weather, we expect the route fixed effects to capture weather effects. To some extent, we expect the same with respect to traffic volume and congestion, even though traffic data provided by the German automobile club (ADAC) does not show significant traffic jams during the sample period.

${ }^{6}$ See http://www.cnr.fr/grilles_couts/e-docs/00/00/00/26/document_grille_ cout.phtml.
} 
direct geographic distance calculations implemented in Stata. We also make use of information on which border-crossings were used along the way. ${ }^{7}$ Prato (2009) provides an up-to-date survey on the challenges in working with route choice data and points out that using shortest point-to-point distances increases similarity within the choice set. Thus, we expect substitutability to be over-estimated and our consumer surplus estimates to be lower bounds. We observe that the large majority of trucks choose the alternative with the minimal price and time. This is intuitive and we therefore expect a negative impact of these variables on choice probabilities in our estimation results. We do observe, however, that a small proportion does not choose the price- and time-minimizing alternative. We can think of two main reasons for this observation. First, there may be a trade-off between time and price logistics firms face and there are some who prefer a longer route to incurring the significant tunnel fees. Second, it could be the result of unobserved heterogeneity related to logistic route choice. In order to reduce fixed costs, logistic firms may choose to combine several loads into one truck. As a consequence, some observations may not be pure Origin-Destination relationships but only the start and end points of a more complex delivery route. Furthermore, depending on the specific good and, for example, their service contract, we expect trucks to have (unobserved) heterogenous preferences for saving money and time. Our time variable is based on typical truck speed and including regular compulsory stops by European law, conditional on the number of drivers per truck. We include per capita GDP of the destination region as a user characteristic to proxy for the value of a vehicle's charge, in addition to the type of commodity. The mean in our sample is closest to per capita GDP in the Netherlands in 2004.

\section{Empirical Framework}

We estimate the loss in user surplus from a hypothetical closure of a major transalpine road tunnel. For example, consider the problem faced by a firm located north of the Alps - say, in France - delivering its product to a downstream producer located south of the Alps - say, in Italy. By our definition, the firm faces eight mutually exclusive route options. While rail could be an option for the firm, we restrict our analysis to road freight. Even though we are forced to this restriction by our data, ${ }^{8}$ modal choice typically depends heavily on the type of commodities and logistic specificities and is, thus, largely predetermined in our choice situations. We further motivate excluding modal choice for our setup in

\footnotetext{
${ }^{7}$ Our attempts to obtain shortest-link route distances from routing service providers such as Google Maps or Navteq failed, unfortunately. Thus, while we have a decent long-distance approximation based on manual checks on a small sub-sample of routes, we need to assume that no significant bias results from ignoring the fact that roads are not straight lines.

${ }^{8}$ For the same reason, our analysis is short-term in that we employ a static choice model and do not allow for market growth or decline through an outside option.
} 


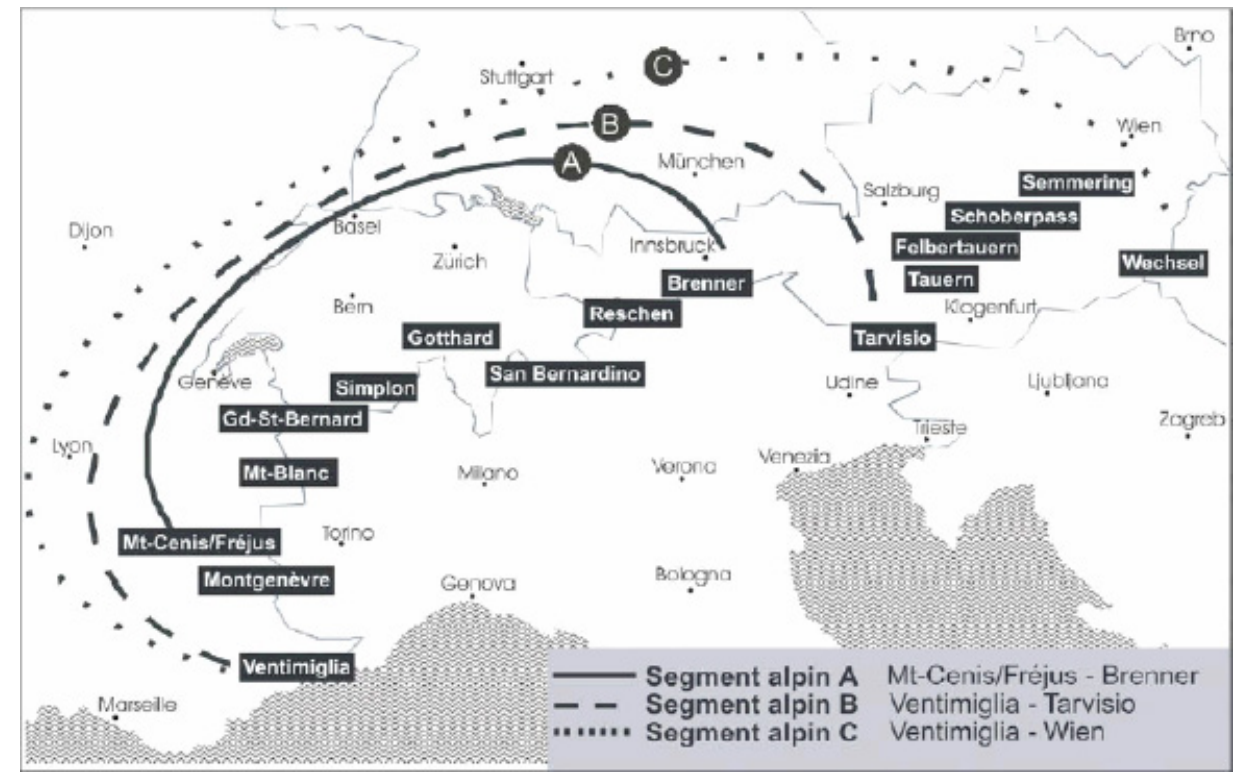

Figure 1: The Alpine corridor. Source: AlpInfo, Federal Office of Transport, Swiss Confederation.

Section 3.3.

We adopt a discrete choice framework ${ }^{9}$ where the choice set is defined by eight west-alpine crossings and the decision makers are individual freight trucks. In particular, user $i$ maximizes the benefit to be obtained from a delivery trip through the Alps and faces $j$ mutually exclusive routes. Thus, the objective function is

$$
U_{i j}=\alpha_{i}\left(r_{i}-p_{i, j}\right)+x_{i, j} \beta_{i}+\xi_{j}+\epsilon_{i j},
$$

where $r_{i}$ is the firm's revenue from the transaction, $p_{i, j}$ the price for alternative $j$ and $x_{i, j}$ route characteristics, which both may contain interaction terms with individual characteristics, $\xi_{j}$ is a constant unobserved route characteristic, and $\epsilon_{i j}$ is assumed to be independently and identically type I extreme value distributed. We have detailed user-specific information, such as GDP in destination and origin regions, commodity class, goods weight, vehicle type, location of vehicle ownership, and so on, allowing us to control for a range of observed user characteristics. However, we expect there are still user characteristics we cannot observe, such as en route pick-ups of goods, truck drivers' personal tastes, or special logistic needs that favor one route over another. It is common practice to model such unobserved heterogeneity by assuming parametric distributions for the relevant taste parameters. However, when estimating welfare measures, too strict assumptions

\footnotetext{
${ }^{9}$ See Train (2009), McFadden and Train (2000), and Hensher and Green (2003) for in-depth treatments.
} 
will lead to biased results. Cherchi and Polak (2005) warn that assuming common mixing distributions such as the normal and log-normal may bias welfare estimations due to an inadequate representation of the true underlying distribution of tastes. Hensher and Greene (2003) give similar warnings and offer a range of simple ways for investigating sensible distributional assumptions. ${ }^{10}$ BFKR propose a mixtures estimator that is nonparametric in the distribution of random coefficients. We have no good prior as to how our taste parameters should be distributed. We further would like to avoid assuming distributions that force portions of decision makers to have negative and unreasonably large coefficients, such as the normal distribution. Hence, we estimate both parametric and nonparametric specifications ${ }^{11}$ and compare the welfare results.

\subsection{Parametric Specification}

We first model user heterogeneity such that taste parameters take the following form:

$$
\left(\begin{array}{c}
\alpha_{i} \\
\beta_{i}
\end{array}\right)=\left(\begin{array}{c}
\alpha \\
\beta
\end{array}\right)+\Pi D_{i}+\Sigma \nu_{i}
$$

where

$$
\nu_{i} \sim \mathbb{N}(0, \mathbb{I})
$$

and $D_{i}$ is a vector of user specific characteristics in our data. User i chooses route $\mathrm{j}$ if and only if $U\left(D_{i}, \nu_{i}, p_{i, j}, x_{i, j}, \xi_{j} ; \theta\right) \geq U\left(D_{i}, \nu_{i}, p_{i, l}, x_{i, l}, \xi_{l} ; \theta\right)$ for $l=1, \ldots, J$. The individual choice probability for route $j$ follows:

$$
P_{i j}=\int_{\theta} \frac{\exp \left(x_{i, j} \beta_{i}-p_{i, j} \alpha_{i}+\xi_{j}\right)}{\sum_{l} \exp \left(x_{i, l} \beta_{i}-p_{i, l} \alpha_{i}+\xi_{l}\right)} f(\alpha) f(\beta) d(\alpha) d(\beta)
$$

where we assume $f(\alpha)$ and $f(\beta)$ to be normal distributions as defined in Equation 2 . We estimate the parameters $\theta$ by maximum simulated likelihood. In the multinomial logit with fixed coefficients, $\alpha$ and $\beta$ are constant across individuals so that the index $i$ is dropped.

\footnotetext{
${ }^{10}$ One straight-forward proposition is a jack-knife approach where the researcher estimates fixed coefficient logit models on sub-samples and evaluates the distributions of estimated coefficients expected to have a non-degenerate distribution.

${ }^{11}$ We also coded the EM algorithm proposed by Train (2008) but encountered severe convergence problems, a common problem with EM algorithms. Fosgerau and Hess (2009) use the method of sieves to increase flexibility. They investigate the ability to recover taste distributions using two flexible approaches: In the first, they add a series expansion to a continuous base distribution using Legendre Polynomials. In the second, they employ discrete mixtures of normal distributions.
} 


\subsection{Nonparametric Specification}

BFKR propose a general nonparametric sieve estimator of unobserved heterogeneity in a wide range of economic models. Their motivating example for the random coefficients logit model lends directly to our analysis. The idea is that the researcher has some prior over the dimensionality and range of random coefficients, that is, of unobserved heterogeneity in the utility function. Assume there are $r=1, \ldots, R$ preference types in the population. We then specify a grid over the assumed support of random coefficients $\beta$. At each grid point, that is for each type $r$, we compute the predicted logit choice probabilities at $x_{i, j}$

$$
g_{j}\left(x_{i, j}, \beta^{r}\right)=\frac{\exp \left(x_{i, j}^{\prime} \beta^{r}\right)}{\sum_{j=1}^{J} \exp \left(x_{i, j}^{\prime} \beta^{r}\right)} .
$$

Treating these predicted probabilities as data, a simple linear regression with $R$ predicted choice probabilities as regressors yields estimates of $R$ weights. The left-hand side variable in this regression, $y_{i, j}$, holds the observed choices. The estimated weights are probability mass points representing the probability of observing type $r$ in the population. Constraining probability masses to the unit interval and their sum to be equal to one, we obtain a discrete approximation to the true distribution of random coefficients. The resulting implementation is a linear inequality constrained OLS estimator.

One drawback of this simple model is the researcher's need to specify the support region where the random coefficients lie. If the latter is unknown, BFKR propose a location scale model that allows to both estimate the location of the support region and its scale. We have no good prior of the support region and thus proceed with the location scale model. A further practical advantage of the latter is the straight-forward inclusion of fixed coefficients. This is an open issue in the linear estimator, given that, by definition, fixed coefficients are nonlinear parameters in the logit model. In the location scale model, the weights $\theta$ still enter linearly. However, the location and scale parameters for our grid and the fixed coefficients enter non-linearly, analogously to the simple logit model. The nonlinear estimator solves the constrained least squares problem

$$
\begin{array}{r}
\min _{a, b, \theta} \frac{1}{N J} \sum_{i=1}^{N} \sum_{j=1}^{J}\left(y_{i, j}-\sum_{r=1}^{R} \theta^{r} g_{j}\left(x_{i, j}, a+b \beta^{r}\right)\right)^{2} \\
\text { subject to } \quad \sum_{r=1}^{R} \theta^{r}=1 \text { and } \theta^{r} \geq 0
\end{array}
$$

where $a=\left(a_{1}, \ldots, a_{K}\right)^{\prime}$ is a set of location parameters, $b=\left(b_{1}, \ldots, b_{K}\right)$ a set of 
scale parameters, $\theta^{r}$ the weight for the parameter vector $\beta^{r}=\left(\beta_{1}^{r}, \ldots, \beta_{K}^{r}\right)$, and

$$
g_{j}\left(x_{i, j}, a+b \beta^{r}\right)=\frac{\exp \left(\sum_{k=1}^{K} x_{k, i, j}\left(a_{k}+b_{k} \beta_{k}^{r}\right)\right)}{\sum_{j=1}^{J} \exp \left(\sum_{k=1}^{K} x_{k, i, j}\left(a_{k}+b_{k} \beta_{k}^{r}\right)\right)} .
$$

We estimate scale parameters $b_{K}$ for random coefficients and set $b_{K}=0$ for coefficients assumed to be fixed. We could allow all coefficients to be random but, as common with nonparametric estimators, we reach computational limits fast when increasing the number of random coefficients. Having reasonable starting values is important in nonlinear least squares estimation. We use the fixed coefficient logit estimates for the nonlinear parameters and $\frac{1}{R}$ for $\theta^{r}$. Experimenting with starting values of the nonlinear parameters, we find our results are very robust to large variations in starting values. We still need to specify $R$ grid points in the unit interval. To do so, we use the Modified Latin Hypercube Sampling method proposed by Hess et al. (2006). Compared to Halton methods, the latter has the advantage of avoiding undesired correlation patterns across dimensions while providing more uniform coverage in each dimension, and being simpler to implement.

\subsection{Identification}

Given their regulated nature, tolls for individual tunnels and long-distance routes vary little across time and routes. Thus, to identify demand patterns, we use individual-level variation from users' geographic dispersion across Europe. In particular, users' origin and destination locations vary relative to the locations of alpine passages. This leads to variation both in route characteristics and individual choices. As road and tunnel tolls are not set strategically, we are confident they are not correlated with the error term. There are two factors that may affect both route choice and travel time. First, congestion may cause short-term deviation to an alternative route. On French passages, however, congestion is not a relevant problem. The Alpine Traffic Observatory, established by the European Commission and the Swiss government in 2007, finds that the Frejus and Mont Blanc tunnels rarely suffer from congestion due to heavy-duty vehicles. ${ }^{12}$ Second, severe weather conditions may cause deviation to alternative routes while increasing travel time. Unfortunately, we cannot fully correct for this potential problem as only parts of our data have information on the date of the choice situation. ${ }^{13}$ Once we are willing to assume that truck drivers form long-term expectations on

\footnotetext{
${ }^{12}$ See, for example, the Observatory's executive summary, page 6, at http://ec.europa.eu/ transport/road/doc/executive_summary_alpine_observatory_en.pdf.

${ }^{13} \mathrm{We}$ did collect daily weather data for the different passages but were unable to obtain survey dates for the Swiss part of the data. This applies to congestion data analogously.
} 
potential obstacles for each route alternative, ${ }^{14}$ we argue it is plausible to believe that the alternative fixed effects will capture much, if not all, potential bias.

Implicitly, we assume that we observe each individual's entire choice set and that there is no outside good. While in the long run freight expeditors may switch to other modes such as air, rail, and sea or even decide not to ship, in the short run this is very unlikely. In the first two columns of Table 4, showing market shares of alternatives before and after the Mont Blanc tunnel closure in 1999, we cannot observe a remarkable shift in market shares towards any of the three rail passages in the short-run. ${ }^{15}$ We also do not observe a downward shift in monthly tons transported after the closure, suggesting that traffic fully deviated to alternative road passages. We interpret this as evidence that modal shift is not yet as relevant as it may be elsewhere. That interpretation is in line with anecdotal evidence on freight transport in France and Italy, citing specific logistic needs, the importance of geographical location, and freight terminals being major bottlenecks as just a few of many remaining problems preventing increased modal shift. ${ }^{16}$ While an important issue in general, we conclude that observing only one mode is a minor drawback in our analysis.

Bajari et al. (2009) prove nonparametric identification of the distribution of random coefficients by exploiting the logit distributional assumptions on $\epsilon_{i j}$ and without relying on large support (as compared to, for example, Berry and Haile, 2010) and monotonicity restrictions. The latter makes their identification result particularly relevant for applied work. A limitation is that their proof is valid only for continuous regressors. Both regressors, for which we assume random coefficients, are continuous.

\section{Estimation results}

We report results for three models of heterogeneity. These are the simple logit, the random coefficients logit with a normal distribution assumption, and the nonparametric BFKR estimator of the random coefficient distribution. ${ }^{17}$ For conciseness, we will refer to these as Logit, RC Logit, and BFKR, respectively. In the Logit specification, observed heterogeneity in preferences can be identified by interacting individual characteristics with route characteristics. Unobserved heterogeneity is limited to the extreme value error term, which is assumed to be independent of route characteristics. The Logit specification serves as an easy

\footnotetext{
${ }^{14}$ Deviating from a planned route is often prohibitive in terms of cost and time.

${ }^{15}$ Due to missing time information at the individual level, our data do not allow direct estimation of the switch to rail and alternative roads caused by the Mont Blanc tunnel closure.

${ }^{16}$ See Andrews (2001), Lange and Ruffini (2007), and Peter Brett Associates LLP (2010).

${ }^{17}$ We run our parametric estimations using the mixlogit Stata command by Hole (2007). For nonparametric estimations, inference, and compensating variation, Matlab code is available from the authors on request.
} 
reference point lending well to the investigation of a variety of utility specifications. It also provides reasonable starting values for the $\mathrm{RC}$ Logit and BFKR models. In the latter two, we report two specifications with one and two random coefficients, respectively. In the RC Logit, we assume random coefficients to be normally distributed, which is by far the most common distribution assumption in the literature employing random coefficients logit models. In the BFKR model, we make no assumption on the form of preference distribution whatsoever but assume that our discrete approximation is a valid representation of the true distribution. All specifications include price-GDP interactions, route fixed effects, and route fixed effects interacted with the weight of the goods transported. We further include route-commodity class fixed effects and time-commodity class interaction terms as well as route fixed effects interacted with dummies indicating traffic connecting Italy with regions west and north of the Alps to capture further observed heterogeneity important to route choice.

Tables 2 reports estimations results with one random coefficient, Table 3 reports results with two. Both tables show that the estimated coefficients have signs as expected. In particular, price and time have negative signs. The coefficients of the interaction terms between weight of goods transported and the alternative specific constants show that heavily loaded trucks are less likely to use Swiss passages and the Montgenevre passage. ${ }^{18}$ This corresponds to our expectation that the Montgenevre pass, having the highest elevation, is less attractive to heavy vehicles likely due to increased fuel consumption and safety concerns on steep slopes. In Switzerland, extra incentives are given for transiting heavy goods vehicles to switch to rail on their passage through the Alps. While we account for monetary incentives by including the extra fees in our price variable, the weight interaction terms may capture further incentives we cannot observe in our data.

In Table 2, price coefficients are higher, in absolute terms, in the RC Logit and BFKR specifications than in the Logit. Hence, not modeling unobserved heterogeneity not only fails to account for the spread of preferences but also biases the estimated means. The means and standard deviations of the price coefficient are significant in both random coefficient specifications. Figure 4 shows a decent Gaussian shape, confirming our parametric distribution assumption in the RC Logit. Hence, we can be reasonably confident that unobserved heterogeneity with respect to price plays an important role in our freight transport setting. In Table 3, we allow individuals to have heterogenous (and potentially correlated) preferences over both price and time. Interpreting the RC Logit result, where the standard deviation of the time coefficient is not statistically different from zero, we conclude the estimated distribution to be degenerate. In economic terms, we may be tempted to conclude that there is no unobserved heterogeneity in preferences over time. Observing the BFKR estimates in Figure 4, however, we

\footnotetext{
${ }^{18}$ The base category both for the alternative specific constants and for the interaction term with good weights is alternative 5 , the Mediterranean passage at Vintimille.
} 
Table 2: Results with one random coefficient (1)

\begin{tabular}{|c|c|c|c|c|}
\hline & \multirow{2}{*}{ Logit } & \multicolumn{2}{|c|}{ RC Logit } & \multirow{2}{*}{ BFKR } \\
\hline & & Mean & $\mathrm{SD}$ & \\
\hline Price & $\begin{array}{c}-8.478^{* * *} \\
(.118)\end{array}$ & $\begin{array}{c}-9.298 * * * \\
(.149)\end{array}$ & $\begin{array}{l}1.523^{* * *} \\
(.079)\end{array}$ & $\begin{array}{c}\text { See } \\
\text { Figure } 4\end{array}$ \\
\hline Time & $\begin{array}{l}-.922^{* * * *} \\
(.230)\end{array}$ & $\begin{array}{l}-.869 * * * \\
(.232)\end{array}$ & & $\begin{array}{l}-.854 * * * \\
(.040)\end{array}$ \\
\hline Price $\times \mathrm{GDP}_{\text {destination }}$ & $\begin{array}{c}1.153^{* * * *} \\
(.294)\end{array}$ & $\begin{array}{l}1.533^{* * * *} \\
(.317)\end{array}$ & & $\begin{array}{c}1.096 \text { *** } \\
(.001)\end{array}$ \\
\hline Mont Blanc & $\begin{array}{l}4.214^{* * *} \\
(.280)\end{array}$ & $\begin{array}{l}4.291^{* * * *} \\
(.297)\end{array}$ & & $\begin{array}{c}3.969 * * * \\
(.243)\end{array}$ \\
\hline$\times$ Weight & $\begin{array}{l}.008 \\
(.006)\end{array}$ & $\begin{array}{l}.010 \\
(.006)\end{array}$ & & $\begin{array}{l}.014^{* * *} \\
(.001)\end{array}$ \\
\hline Frejus & $\begin{array}{c}5.144^{* * *} \\
(.234)\end{array}$ & $\begin{array}{l}5.256^{* * *} \\
(.254)\end{array}$ & & $\begin{array}{c}4.488^{* * * *} \\
(.318)\end{array}$ \\
\hline$\times$ Weight & $\begin{array}{l}.020 * * * \\
(.005)\end{array}$ & $\begin{array}{l}.023^{* * *} \\
(.006)\end{array}$ & & $\begin{array}{l}.026^{* * *} \\
(.002)\end{array}$ \\
\hline Montgenevre & $\begin{array}{c}-5.843^{* * *} \\
(.552)\end{array}$ & $\begin{array}{c}-6.657^{* * *} \\
(.657)\end{array}$ & & $\begin{array}{c}-4.886^{* * *} \\
(.291)\end{array}$ \\
\hline$\times$ Weight & $\begin{array}{l}-.031^{* * *} \\
(.009)\end{array}$ & $\begin{array}{l}-.036^{* * * *} \\
(.010)\end{array}$ & & $\begin{array}{l}-.024^{* * *} \\
(.005)\end{array}$ \\
\hline Gd St-Bernard & $\begin{array}{l}.154 \\
(.310)\end{array}$ & $\begin{array}{l}.178 \\
(.332)\end{array}$ & & $\begin{array}{l}.632^{* * *} \\
(.065)\end{array}$ \\
\hline$\times$ Weight & $\begin{array}{l}-.058^{* * *} \\
(.009)\end{array}$ & $\begin{array}{l}-.063^{* * *} \\
(.010)\end{array}$ & & $\begin{array}{l}-.072^{* * * *} \\
(.004)\end{array}$ \\
\hline Simplon & $\begin{array}{r}-.095 \\
(.310)\end{array}$ & $\begin{array}{r}-.113 \\
(.330)\end{array}$ & & $\begin{array}{l}.428^{* * *} \\
(.089)\end{array}$ \\
\hline$\times$ Weight & $\begin{array}{l}-.047 * * * \\
(.010)\end{array}$ & $\begin{array}{l}-.051^{* * *} \\
(.010)\end{array}$ & & $\begin{array}{l}-.085 * * * \\
(.004)\end{array}$ \\
\hline St. Gotthard & $\begin{array}{l}3.576^{* * *} \\
(.293)\end{array}$ & $\begin{array}{l}3.730 * * * \\
(.312)\end{array}$ & & $\begin{array}{c}4.128 * * * \\
(.196)\end{array}$ \\
\hline$\times$ Weight & $\begin{array}{l}-.073^{* * *} \\
(.007)\end{array}$ & $\begin{array}{l}-.076^{* * *} \\
(.007)\end{array}$ & & $\begin{array}{c}-.096^{* * *} \\
(.007)\end{array}$ \\
\hline San Bernadino & $\begin{array}{l}2.654^{* * * *} \\
(.297)\end{array}$ & $\begin{array}{l}2.789^{* * * *} \\
(.316)\end{array}$ & & $\begin{array}{c}3.282^{* * *} \\
(.102)\end{array}$ \\
\hline$\times$ Weight & $\begin{array}{l}-.073^{* * *} \\
(.008)\end{array}$ & $\begin{array}{l}-.075^{* * *} \\
(.008)\end{array}$ & & $\begin{array}{l}-.090^{* * *} \\
(.005)\end{array}$ \\
\hline Likelihood ratio & 105342.50 & 130 & & \\
\hline Prob $>\chi^{2}$ & .000 & .0( & & \\
\hline Pseudo $R^{2}$ & .71 & & & \\
\hline
\end{tabular}

Notes: All specifications include route dummy-commodity class and time-commodity class interaction terms as well as route dummies interacted with dummies indicating traffic connecting Italy with regions west and north of the Alps, respectively. The reference route is the Mediterranean crossing at Vintimille. Standard errors are reported in parenthesis, choice situation-clustered robust standard errors in BFKR estimation. 500 Halton draws used for simulations in parametric random coefficients logit estimations. 285,656 observations.

$* * * \mathrm{p}<0.01,{ }^{* *} \mathrm{p}<0.05,{ }^{*} \mathrm{p}<0.1$ 
clearly see significant heterogeneity both in preferences over price and time. A priori, it is not obvious which distribution to assume. It is difficult to proceed in an ad-hoc fashion by assuming various readily available parametric distributions and using the ones yielding significant parameters estimates. There is no clear rule which and how many parametric distributions to investigate before 'giving up' and coming to the conclusion that here may be no unobserved heterogeneity in the data.

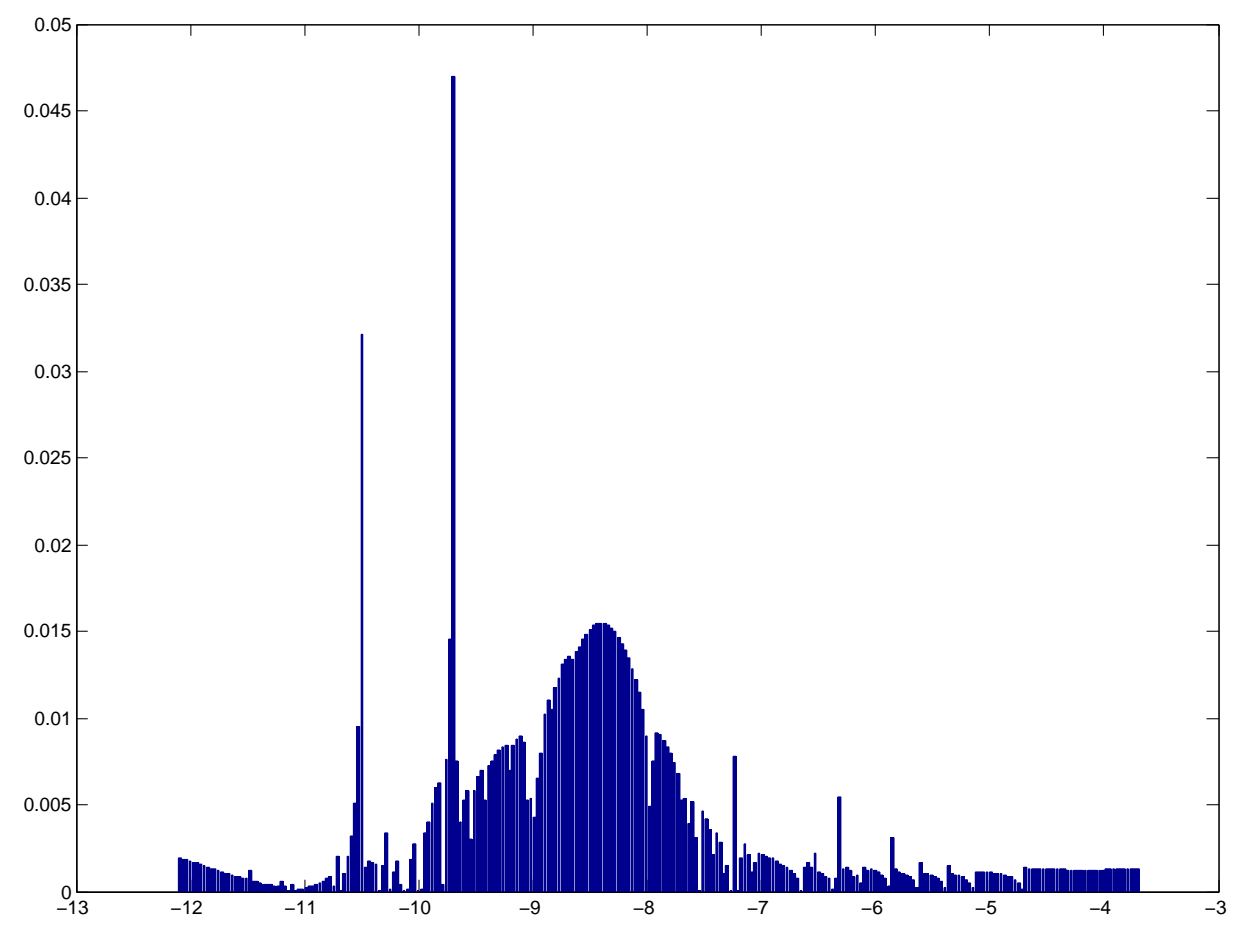

Figure 2: Distribution of price coefficient from BFKR estimation in Table 2. Regimes $\mathrm{R}=274$.

The main assumption in BFKR is that their sieve estimator is a discrete approximation of the true distribution. Therefore, the number of grid points is a key parameter the researcher needs to define. It is limited by sample size and computer memory. With 8GB RAM and our sample size of 35,707 choice situations, we are able to set $\mathrm{R}=274$ with one and $\mathrm{R}=256$ with two random coefficients, that is $R=\frac{N}{130}$ whereas BFKR propose $R=\frac{N}{40}$ in their Monte Carlo experiment. Furthermore, to use parametric methods for computing standard errors of the BFKR estimates, we need to assume that the grid points $r$ are the true types that generated the data. Unless we can specify an almost infinite number of $r$, estimated probability mass points and thus their standard errors can only be approximations to the truth. We compute $95 \%$ confidence intervals, following BFKR and Gallant (1975), using standard errors from unconstrained nonlinear 
Table 3: Results with two correlated random coefficients (2)

\begin{tabular}{|c|c|c|c|c|}
\hline & \multirow{2}{*}{ Logit } & \multicolumn{2}{|c|}{ RC Logit } & \multirow{2}{*}{ BFKR } \\
\hline & & Mean & $\mathrm{SD}$ & \\
\hline Price & $\begin{array}{c}-8.478^{* * *} \\
(.118)\end{array}$ & $\begin{array}{c}-9.244^{* * *} \\
(.148)\end{array}$ & $\begin{array}{l}1.273^{* * * *} \\
(.078)\end{array}$ & \multirow{2}{*}{$\begin{array}{c}\text { See } \\
\text { Figure } 4\end{array}$} \\
\hline Time & $\begin{array}{l}-.922^{* * * *} \\
(.230)\end{array}$ & $\begin{array}{c}-1.504^{* * * *} \\
(.266)\end{array}$ & $\begin{array}{l}.271 \\
(.291)\end{array}$ & \\
\hline Price $\times \mathrm{GDP}_{\text {destination }}$ & $\begin{array}{l}1.153^{* * *} \\
(.294)\end{array}$ & \multicolumn{2}{|l|}{$\begin{array}{l}1.520^{* * *} \\
(.322)\end{array}$} & $\begin{array}{c}1.160^{* * *} \\
(.001)\end{array}$ \\
\hline Mont Blanc & $\begin{array}{l}4.214^{* * *} \\
(.280)\end{array}$ & \multicolumn{2}{|l|}{$\begin{array}{c}4.276^{* * *} \\
(.293)\end{array}$} & $\begin{array}{c}5.913^{* * *} \\
(.316)\end{array}$ \\
\hline$\times$ Weight & $\begin{array}{l}.008 \\
(.006)\end{array}$ & \multicolumn{2}{|l|}{$\begin{array}{l}.010^{*} \\
(.006)\end{array}$} & $\begin{array}{l}.018^{* * *} \\
(.002)\end{array}$ \\
\hline Frejus & $\begin{array}{l}5.144^{* * * *} \\
(.234)\end{array}$ & \multicolumn{2}{|l|}{$\begin{array}{l}5.254^{* * *} \\
(.248)\end{array}$} & $\begin{array}{l}6.753^{* * *} \\
(.403)\end{array}$ \\
\hline$\times$ Weight & $\begin{array}{l}.020 * * * \\
(.005)\end{array}$ & \multicolumn{2}{|l|}{$\begin{array}{l}.023^{* * *} \\
(.005)\end{array}$} & $\begin{array}{l}.032^{* * * *} \\
(.003)\end{array}$ \\
\hline Montgenevre & $\begin{array}{c}-5.843^{* * *} \\
(.552)\end{array}$ & \multicolumn{2}{|l|}{$-6.638 * * *$} & $\begin{array}{c}-5.318^{* * *} \\
(.319)\end{array}$ \\
\hline$\times$ Weight & $\begin{array}{l}-.031^{* * *} \\
(.009)\end{array}$ & \multicolumn{2}{|l|}{$\begin{array}{l}-.035^{* * *} \\
(.010)\end{array}$} & $\begin{array}{c}-.013^{* * *} \\
(.003)\end{array}$ \\
\hline Gd St-Bernard & $\begin{array}{l}.154 \\
(.310)\end{array}$ & \multicolumn{2}{|l|}{$\begin{array}{l}.237 \\
(.332)\end{array}$} & $\begin{array}{l}1.553^{* * *} \\
(.067)\end{array}$ \\
\hline$\times$ Weight & $\begin{array}{l}-.058 * * * \\
(.009)\end{array}$ & \multicolumn{2}{|l|}{$\begin{array}{l}-.065^{* * *} \\
(.010)\end{array}$} & $\begin{array}{l}-.071^{* * *} \\
(.004)\end{array}$ \\
\hline Simplon & $\begin{array}{r}-.095 \\
(.310)\end{array}$ & \multicolumn{2}{|l|}{$\begin{array}{r}-.064 \\
(.330)\end{array}$} & $\begin{array}{l}1.485^{* * *} \\
(.089)\end{array}$ \\
\hline$\times$ Weight & $\begin{array}{l}-.047 * * * \\
(.010)\end{array}$ & \multicolumn{2}{|l|}{$\begin{array}{l}-.053^{* * *} \\
(.011)\end{array}$} & $\begin{array}{l}-.092^{* * *} \\
(.004)\end{array}$ \\
\hline St. Gotthard & $\begin{array}{l}3.576^{* * * *} \\
(.293)\end{array}$ & \multicolumn{2}{|l|}{$\begin{array}{l}3.818^{* * * *} \\
(.310)\end{array}$} & $\begin{array}{l}5.434^{* * *} \\
(.225)\end{array}$ \\
\hline$\times$ Weight & $\begin{array}{l}-.073^{* * *} \\
(.007)\end{array}$ & \multicolumn{2}{|l|}{$\begin{array}{l}-.077^{* * *} \\
(.007)\end{array}$} & $\begin{array}{l}-.109^{* * *} \\
(.008)\end{array}$ \\
\hline San Bernadino & $\begin{array}{l}2.654^{* * * *} \\
(.297)\end{array}$ & \multicolumn{2}{|l|}{$\begin{array}{l}2.872^{* * *} \\
(.314)\end{array}$} & $\begin{array}{l}4.509 * * * \\
(.115)\end{array}$ \\
\hline$\times$ Weight & $\begin{array}{l}-.073^{* * *} \\
(.008)\end{array}$ & \multicolumn{2}{|l|}{$\begin{array}{l}-.076^{* * *} \\
(.008)\end{array}$} & $\begin{array}{l}-.102^{* * *} \\
(.006)\end{array}$ \\
\hline Likelihood ratio & 105342.50 & \multicolumn{2}{|c|}{262.77} & \\
\hline Prob $>\chi^{2}$ & .000 & \multirow{2}{*}{\multicolumn{2}{|c|}{.000}} & \\
\hline Pseudo $R^{2}$ & .71 & & & \\
\hline
\end{tabular}

Notes: All specifications include route dummy-commodity class and time-commodity class interaction terms as well as route dummies interacted with dummies indicating traffic connecting Italy with regions west and north of the Alps, respectively. The reference route is the Mediterranean crossing at Vintimille. Standard errors are reported in parenthesis, choice situation-clustered robust standard errors in BFKR estimation. 500 Halton draws used for simulations in parametric random coefficients logit estimations. 285,656 observations.

*** $\mathrm{p}<0.01,{ }^{* *} \mathrm{p}<0.05,{ }^{*} \mathrm{p}<0.1$ 


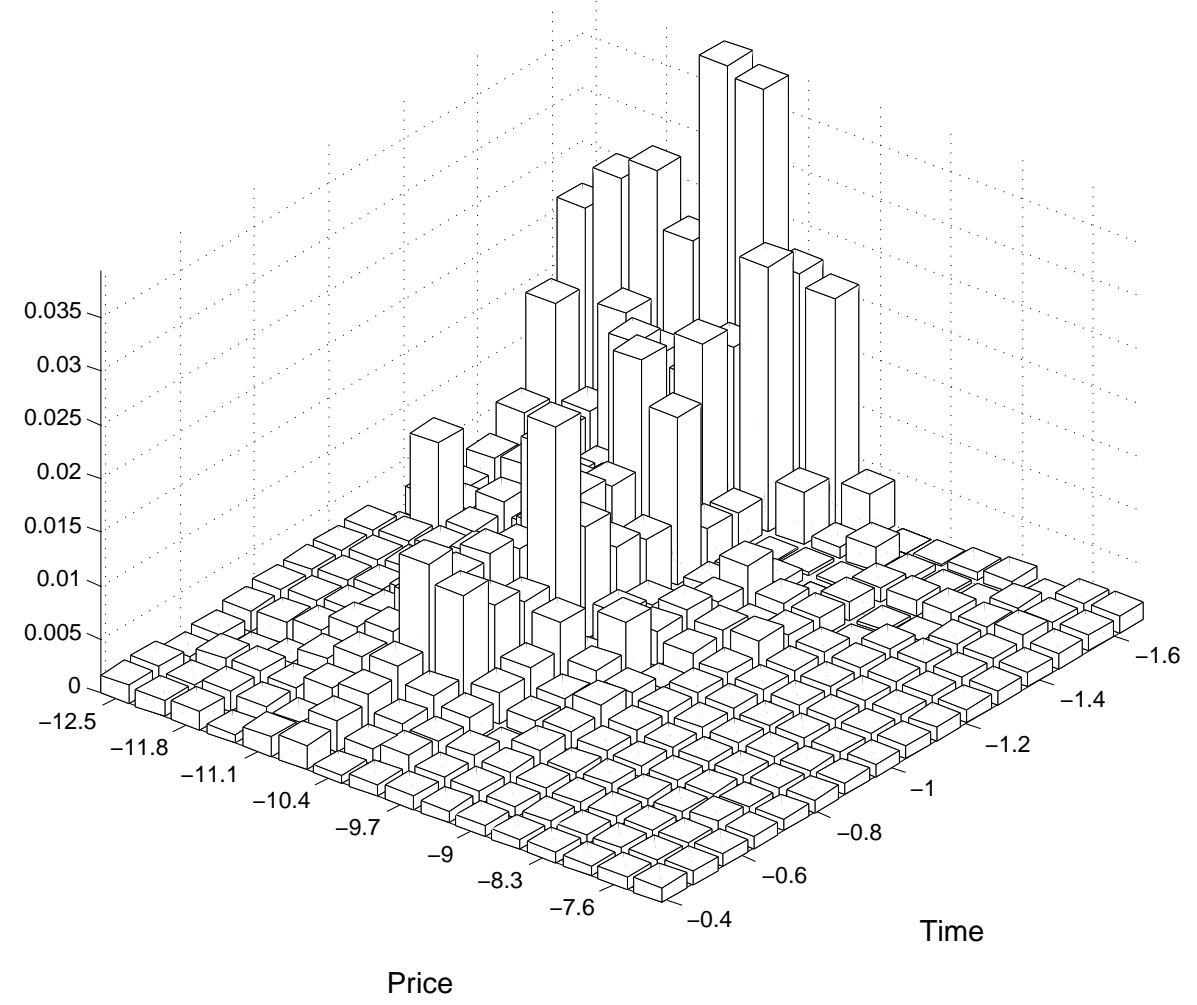

Figure 3: Distribution of price and time coefficients from BFKR estimation in Table 3. Regimes $\mathrm{R}=256$.

regression and clustering by individual choice situations. Confidence intervals are then defined as $C I_{95}=\left[\hat{\theta}^{r}-1.96 \cdot S E\left(\hat{\theta}_{u n c}^{r}\right), \hat{\theta}^{r}+1.96 \cdot S E\left(\hat{\theta}_{u n c}^{r}\right)\right] \cap[0,1]$, where $S E=\sqrt{\hat{\nu}}$ and

$$
\hat{\nu}=\frac{N P}{N P-1}\left(\frac{S S E}{N-p}\left(J^{\prime} J\right)^{-1}\left(\sum_{k=1}^{M}\left(\sum_{j \in G_{k}} u_{j}^{\prime} \sum_{j \in G_{k}} u_{j}\right)\right) \frac{S S E}{N-p}\left(J^{\prime} J\right)^{-1}\right) .
$$

However, as do BFKR, we find these confidence intervals to be very conservative and, thus, too uninformative to report. From our experience with estimations using varying grids sizes, this problem seems to get worse as the number of grid points $\mathrm{R}$ increases and $\theta$ are estimated closer to the zero boundary. Bootstrapping is infeasible as the nonlinear least squares routine consumes significant computing time with the size of our sample and parameter vector. 


\section{Counterfactual Analysis}

\subsection{Diversion patterns}

To verify the structural quality of our estimates, we compare counterfactual shares with those observed after the Mont Blanc tunnel closure in 1999. Road tolls and tunnel fees were not adjusted as a consequence of the closure and there is currently no road congestion pricing on the relevant road network. Thus, we assume there is no strategic pricing and prices remain fixed after a hypothetical future closure of a tunnel. In Table 4, we present the substitution due to a hypothetical closure of the Mont Blanc tunnel in 2004 predicted by the BFKR model with two random coefficients. We compute market shares in the table based on tons transported.

Table 4: Passage Market Shares (\%) - Counterfactual closure in 2004

\begin{tabular}{|c|c|c|c|c|c|}
\hline & \multicolumn{2}{|c|}{1999} & \multicolumn{2}{|c|}{2004} \\
\hline & & Open & Closed & Open & Closed \\
\hline \multirow{8}{*}{ Road } & Mont Blanc & 21.79 & & 10.14 & \\
\hline & Frejus & 27.68 & 44.54 & 32.51 & 35.87 \\
\hline & Montgenevre & 1.09 & 3.38 & 0.67 & 2.31 \\
\hline & Vintimille & 21.26 & 24.36 & 33.76 & 33.31 \\
\hline & Gd St-Bernard & & & 1.19 & 1.99 \\
\hline & Simplon & & & 1.25 & 1.54 \\
\hline & St. Gotthard & & & 18.07 & 21.59 \\
\hline & San Bernadino & & & 2.41 & 3.38 \\
\hline \multirow{3}{*}{ Rail } & Basel (CH) & 10.61 & 10.84 & & \\
\hline & Modane (Frejus) & 15.42 & 15.21 & & \\
\hline & Vintimille & 2.16 & 1.67 & & \\
\hline Mont & tonnage (1000s) & 4,455 & 4,619 & & 38 \\
\hline
\end{tabular}

Notes: 2004 Predictions are simulated using specification (2) of the BFKR model. We use 1000 quasi-random draws to compute choice probabilities.

Table 4 shows that most traffic diverted to the nearby Frejus tunnel when the Mont Blanc option dropped out in 1999. The traffic share at the Mont Blanc dropped from $21.79 \%$ to $0 \%$, causing an increase of the traffic share at the Frejus from $27.68 \%$ to $44.54 \%$. We do not have monthly data for Swiss passages in 1999, limiting comparison to the French passages. A further limitation arises from the fact that, between 1999 and 2004, Switzerland gradually increased weight restrictions for heavy duty transit. For a large share of trucks, Swiss passages were not an available option in 1999 while, in 2004, these limitations were virtually gone. Since 1999, freight traffic through the Mont Blanc tunnel has been reduced significantly, its share being $10.14 \%$ in 2004 . Our counterfactual results show 
the largest shifts from the Mont Blanc tunnel to the Frejus and St. Gotthard passages. While $10.14 \%$ traffic share need to be compensated by the remaining passages, the traffic share at the Frejus is predicted to increase from $32.51 \%$ to $35.87 \%$ and at the St. Gotthard from $18.07 \%$ to $21.59 \%$. We interpret the similar tendencies on French passages throughout 1999 and 2004 to confirm the fit of the BFKR model but stress the limited comparability of these market shares due to institutional and observational differences.

\subsection{Consumer surplus}

We analyze a hypothetical closure of the Mont Blanc tunnel in 2004 and compute users' compensating variations, that is, the amount of money one would have to give to infrastructure users to maintain their ex ante utility levels. We define the ex ante situation as the reference point, as suggested by Trajtenberg (1989). In the multinomial logit model, abstracting from observed heterogeneity for notational simplicity, computation of the compensating variation is straight forward and given by the difference of the ex post and ex ante values of the logsum measure with no unobserved taste heterogeneity:

$$
C V=\frac{1}{\alpha}\left\{\ln \sum_{j} \exp \left(\beta^{\prime} x_{j}^{\text {pre }}\right)-\ln \sum_{j} \exp \left(\beta^{\prime} x_{j}^{\text {post }}\right)\right\}
$$

As the random coefficients logit model introduces unobserved taste heterogeneity, each individual now may have her own valuation of route characteristics. We integrate over the estimated mixing distributions by simulation and compute the mean and total compensating variation. This is where the how we model heterogeneity comes in. With random coefficients, any distributional assumption has a direct impact on the consumer surplus measure which, following Train (1998) and von Haefen (2003), we compute as:

$$
C V_{i}=\int \frac{1}{\alpha_{i}}\left\{\ln \sum_{j} \exp \left(\beta^{\prime} x_{i, j}^{p r e}\right)-\ln \sum_{j} \exp \left(\beta^{\prime} x_{i, j}^{\text {post }}\right)\right\} f\left(\alpha \mid \theta^{\text {pre }}\right) d(\alpha)
$$

Equations 5 and 6 imply the assumption that the marginal utility of income, $\alpha_{i}$, is independent of income. That is, indirect utility is additive and linear in income. While this is a restrictive assumption, Train (2009) points out, on page 57 , that it needs to hold only 'over the range of implicit income changes that are considered by the policy'. This means that if individual compensating variations are low relative to income, which is arguably true for our case, the assumption does not need to hold in general but only for the considered small range. Maintaining this assumption significantly simplifies our computations. We solve Equation 6 for each individual via simulation by sampling from the estimated 
mixing distributions. To obtain the population mean and total change in user benefits, we weight the estimated sample means of compensating variations using the expansion factor in the CAFT 2004 data.

Table 5: Welfare effects of tunnel closure

\begin{tabular}{|c|c|c|c|c|c|}
\hline \multirow{2}{*}{$\begin{array}{l}\text { Compensating } \\
\text { variation } \\
\text { (in 2004 Euros) }\end{array}$} & \multirow[t]{2}{*}{ Logit } & \multicolumn{2}{|c|}{ RC Logit } & \multicolumn{2}{|c|}{ BFKR } \\
\hline & & (1) & $(2)$ & $(1)$ & $(2)$ \\
\hline Sample mean & 1.11 & .84 & .69 & 1.80 & 1.39 \\
\hline Population mean & 1.28 & .96 & .79 & 1.88 & 1.43 \\
\hline Population total (Mio) & 4.83 & 3.62 & 2.97 & 7.09 & 5.39 \\
\hline
\end{tabular}

In Table 5, we report the compensating variation for closing the Mont Blanc tunnel as the unweighted and weighted means over the sampled individuals, and as the weighted sum yielding the population total. The BFKR estimates imply economically significantly higher losses in user surplus. With two random coefficients, the BFKR estimate implies a loss of $€ 5.39$ Mio and the RC Logit a loss of $€ 2.97$ Mio. With one random coefficient, the BFKR estimate is almost double that of the RC Logit estimate, $€ 7.09$ Mio versus $€ 3.62$ Mio. Compared to both the Logit and the BFKR estimates, both RC Logit specifications underestimate the loss in consumer surplus. We admit that a more informative comparison would include confidence intervals for these estimates. These can be computed using the delta method. However, they rely on the estimated variances of $\hat{\theta}^{r}$. Since there is currently no method to estimate correct confidence intervals, for the reasons elaborated in Section 4, we are not able to provide these inference results for our welfare estimates. The large relative differences between the RC Logit and BFKR results strongly suggest, however, that modeling unobserved heterogeneity in a more flexible way can lead to severely differing economic conclusions.

\section{Conclusion}

Estimating welfare implications of specific policy measures is relevant in many economic applications. The discrete choice framework provides a convenient way to estimate the compensating variation, for example for changes in choice sets or in product characteristics, when individuals face a set of mutually exclusive choices. It is well known, that modeling heterogeneity is key to understanding preferences and hence to quantify consumer surplus. While the random coefficients logit model offers a highly flexible way to approximate any random utility model arbitrarily well, it hinges on the assumption that the researcher knows 
the correct distribution of random coefficients a priori. While estimating welfare effects is a common exercise in many applications, we are not aware of many studies exploring the role of unobserved heterogeneity in this context. We provide insights into the importance of how unobserved heterogeneity is modeled when estimating welfare effects of policy measures. We do so by comparing consumer surplus estimates from a recently proposed nonparametric estimator of preference distributions and the standard parametric random coefficients logit model. To our knowledge, we are the first to apply the BFKR estimator to real-world data in a random coefficients logit setting. Employing revealed preference data, we analyze the implications of a much debated transport policy measure: the closure of the alpine Mont Blanc tunnel to freight traffic.

We estimate the annual loss in user benefits ranges from 2.97 to 3.62 million Euros in the RC Logit model, while our BFKR estimates imply annual losses ranging from 5.39 to 7.09 million Euros. Hence, in our analysis both parametric assumptions and the dimensionality of modeled unobserved heterogeneity have a significant impact on welfare results. We thus caution the exclusive use of standard distributional assumptions in modeling heterogeneity and demonstrate the simple implementation of the BFKR estimator. 


\section{Appendix A Alpine passages}

Our sample includes the following passages:

1. Mont Blanc tunnel

2. Frejus tunnel

3. Montgenevre pass

4. Vintimille expressway (along the Mediterranean coast)

5. Grand St-Bernard tunnel

6. Simplon pass

7. St. Gotthard tunnel

8. San Bernadino pass 


\section{References}

[1] Andrews, Edmund L. (2001), "Soaring Continental Trade Produces Deadly Squeeze at Alpine Tunnels", New York Times, 2 November.

[2] Bajari, Patrick L., Fox, Jeremy T., and Stephen P. Ryan (2007), "Linear Regression Estimation of Discrete Choice Models with Nonparametric Random Coefficient Distributions," American Economic Review: Papers and Proceedings 97(2), 459-463.

[3] Bajari, Patrick L., Fox, Jeremy T., il Kim, Kyoo, and Stephen P. Ryan (2009), The Random Coefficients Logit Model Is Identified, mimeo.

[4] Bajari, Patrick L., Fox, Jeremy T., il Kim, Kyoo, and Stephen P. Ryan (2010), A Simple Nonparametric Estimator for the Distribution of Random Coefficients, mimeo.

[5] Berry, Steven T. and Philip A. Haile (2010), "Nonparametric Identification of Multinomial Choice Demand Models with Heterogeneous Consumers", Cowles Foundation Discussion Paper No. 1718, Yale University.

[6] Bilotkach, Volodymyr, Gorodnichenko, Yuriy, and Oleksandr Talavera (2010), "Sensitivity of Prices to Demand Shocks: A Natural Experiment in the San Francisco Bay Area", University of East Anglia AEP Discussion Paper No. 2010-04, Norwich.

[7] Cherchi, Elisabetta and John W. Polak (2005), "Assessing User Benefits with Discrete Choice Models: Implications of Specification Errors Under Random Taste Heterogeneity," Transportation Research Record 1926, 61-69.

[8] Dolnick, Sam (2010), "Plan to Remove Bronx Expressway Gains Traction", New York Times, 12 July.

[9] European Commission (2001), European Transport Policy for 2010: Time to decide. White Paper, European Commission, Brussels.

[10] European Commission (2006), Aid to Finance Safety Measures in the MontBlanc Tunnel and the Maurice Lemaire Tunnel. Press Release IP/06/206, European Commission, Brussels.

[11] European Parliament (2001), "Reopening of Mont Blanc Tunnel", OJ edition, Debate on 25 October 2001, Strasbourg.

[12] Fosgerau, Mogens and Stephane Hess (2009), "A Comparison of Methods for Representing Random Taste Heterogeneity in Discrete Choice Models," European Transport, 40, 1-25. 
[13] Gallant, A. Ronald (1975), "Nonlinear Regression," The American Statistician 29, 73-81.

[14] Goolsbee, Austan and Amil Petrin (2004), "The Consumer Gains from Direct Broadcast Satellites and the Competition with Cable TV," Econometrica, 72(2), 351-381.

[15] Hensher, David A. and William H. Greene (2003), "The Mixed Logit Model: The State of Practice," Transportation 30(2), 133-176.

[16] Hess, Stephane, Train, Kenneth E., John W. Polak (2006), "On the Use of a Modified Latin Hypercube Sampling (MLHS) Method in the Estimation of a Mixed Logit Model for Vehicle Choice," Transportation Research Part B: Methodological 40(2), 147-163.

[17] Hole, Arne R. (2007), "Fitting Mixed Logit Models by using Maximum Simulated Likelihood," The Stata Journal 7(3), 388-401.

[18] Hynes, Stephen, Hanley, Nick, and Riccardo Scarpa (2008), "Effects on Welfare Measures of Alternative Means of Accounting for Preference Heterogeneity in Recreational Demand Models," American Journal of Agricultural Economics, 90(4), 1011-1027.

[19] Lange, Sandra and Flavio V. Ruffini (2007), "Transalpine Freight Transport: A Call for Joint Measures," Journal of Alpine Research 95(1), 21-32.

[20] McFadden, Daniel L. and Kenneth E. Train (2000), "Mixed MNL Models for Discrete Response," Journal of Applied Econometrics 14(5), 447-470.

[21] Peter Brett Associates LLP (2010), Freight Modal Choice Study: Behavioural Barriers and Factors Influencing Modal Choice. Final Report, Department for Transport, London.

[22] Petrin, Amil (2002), "Quantifying the Benefits of New Products: The Case of the Minivan," Journal of Political Economy, 110(4), 705-729.

[23] Prady, Delphine and Hannes Ullrich (2010), "Entry and Competition in Freight Transport: The Case of a Prospective Transalpine Rail Link Between France and Italy", ZEW Discussion Paper No. 10-010, Mannheim.

[24] Prato, Carlo G. (2009), "Route Choice Modeling: Past, Present and Future Research Directions," Journal of Choice Modelling, 2(1), 65-100.

[25] Train, Kenneth E. (1998), "Recreation Demand Models with Taste Differences over People," Land Economics 74(2), 230-239. 
[26] Train, Kenneth E. (2009), Discrete Choice Models with Simulation, Cambridge University Press, Cambridge.

[27] Train, Kenneth E. (2008), "EM Algorithms for Nonparametric Estimation of Mixing Distributions," Journal of Choice Modeling 1(1), 40-69.

[28] Trajtenberg, Manuel (1989), "The Welfare Analysis of Product Innovations, with an Application to Computed Tomography Scanners," Journal of Political Economy 97(2), 444-479.

[29] Von Haefen, Roger H. (2003), "Incorporating Observed Choice into the Construction of Welfare Measures from Random Utility Models," Journal of Environmental Economics and Management 45(2), 145-165. 